\title{
Long-Term Follow-Up in a Male Patient with Micro-TSH-Oma Diagnosed at 8-Yr-Old
} \author{
Nelson P Ferreira ${ }^{3}$ and Luiz De Lacerda ${ }^{1}$ \\ ${ }^{1}$ Department of Pediatrics, Universidade Federal do Paraná, Curitiba, Brazil \\ ${ }^{2}$ Department of Internal Medicine, Universidade Federal do Rio Grande do Sul, Brazil \\ ${ }^{3}$ Department of Neurosurgery, Santa Casa de Misericórdia de Porto Alegre, Brazil
}

Adriane A Cardoso-Demartini ${ }^{1 *}$, Mauro A Czepielewski ${ }^{2}$, Suzana Nesi-França ${ }^{1}$, Rosana Marques-Pereira $^{1}$,

Submission: July 01, 2019; Published: July 18, 2019

*Corresponding author: Adriane A Cardoso-Demartini, Pediatric Endocrinology Unit, Department of Pediatrics, Federal University of Paraná, Curitiba, Rua Padre Camargo, 250 - Curitiba, PR, Brazil

\begin{abstract}
Background: TSH-secreting pituitary adenomas (TSH-omas) are very rare and an infrequent cause of thyrotoxicosis.

Case Report: A 7.9-yr-old boy was referred to our Pediatric Endocrinology Unit due to a goiter. On admission, patient was thyrotoxic with diffuse goiter. Laboratory evaluation suggested inappropriate TSH secretion as the cause of hyperthyroidism: high serum TSH in presence of elevated levels of $\mathrm{TT}_{4}, \mathrm{TT}_{3}$ and $\mathrm{fT}_{4}$, and TSH unresponsive to TRH stimulation and to $\mathrm{T}_{3}$ suppression. Initially, $\alpha$-subunit (aSU) was in the upper limit of normalcy and pituitary MRI was normal. One year after, patient was still hyperthyroid, despite regular use of methimazole; TSH was 12.6 $\mathrm{mU} / \mathrm{mL}, \alpha \mathrm{SU}$ was elevated and MRI detected a pituitary $8 \mathrm{~mm}$ width adenoma, establishing the diagnosis of TSH-oma. Peak GH (ng/dL) on ITT and TSH after TRH were 5.9 and 4.2, respectively. Cortisol and prolactin (PRL) responded normally to ITT and TRH tests. Transsphenoidal surgery was done and, postoperatively, transient diabetes insipidus and adrenal insufficiency ensued. Two and five months after surgery $\mathrm{fT}_{4}, \mathrm{TT}_{4}$ and $\mathrm{TT}_{3}$ were normal, albeit peak TSH after TRH was 1.54. PRL and GH were unresponsive to adequate stimuli. Fourteen months after surgery, $\mathrm{TT}_{4}$, $\mathrm{TT}_{3}$ and $\mathrm{fT}_{4}$ were low normal. He presented with low IGF-1, low GH peak on dinanic tests and hypogonadism and was treated with recombinant human growth hormone (rhGH) and testostenone. At 16 yr-old, we reached final height, above target height.
\end{abstract}

Conclusion: TSH-oma may be an etiology of thyrotoxicosis in children. To our knowledge, this is one of the youngest patients with TSH-oma yet reported.

Keywords: Pituitary tumor; TSH-oma; Hyperthyroidism; Thyrotoxicosis; Transsphenoidal surgery; Final height

\section{Introduction}

In most children with thyrotoxicosis the main cause is Graves' disease. Other causes include toxic adenoma, thyroiditis, iodine-induced hyperthyroidism, McCune-Albright syndrome, syndrome of resistance to thyroid hormone (RTH) and thytroidstimulating hormone (TSH) secreting pituitary adenoma (TSHoma). TSH-oma comprises 0.5 to $3 \%$ of all pituitary tumors. Patients present with signs and symptoms related to thyroid hormone (TH) excess and/or to tumor size (headache, visual field disturbances, cranial nerve palsies). The presence of goiter is frequent [1,2]. Elevated TH levels in presence of nonsuppressed TSH should occur in TSH-omas, as well as in other conditions such as early phase of destructive thyroiditis, irregular replacement of l-thyroxine, assay interference of heterophilic antibodies and RTH. The combination of high serum free TH, inappropriately normal or elevated TSH, high serum $\alpha$-subunit $(\alpha \mathrm{SU})$ or increased $\alpha \mathrm{SU} / \mathrm{TSH}$ molar ratio and a pituitary tumor strongly suggests the diagnosis of a TSH-oma.

Triiodothyronine (T3) suppression test is generally reserved for patients with inconclusive results in above tests, because genetic tests for detection of mutations in thyroid receptor (TR) $\alpha$ and TR $\beta$ genes are expensive. Administering long-acting somatostatin analogs has been proposed for distinguishing between thyrotropinomas and RTH, since patients with thyrotropinomas would be likely to show a significant reduction in free thyroxine $\left(\mathrm{fT}_{4}\right)$ and $\mathrm{T}_{3}$ levels. Approximately one third of patients with TSH-oma were misdiagnosed as having primary hyperthyroidism and mistakenly treated with thyroidectomy or radioiodine [2]. The majority of TSH-omas is monoclonal in origin, like other types of pituitary adenomas. Pituitary-specific transcription factor-1 (Pit-1) may play a role in adenomatous 
cell proliferation and its overexpression was detected in growth hormone- (GH), prolactin- (PRL) and TSH-secreting adenomas more frequently than in normal pituitary. Reduced expression of TR was demonstrated, and it could explain the abnormal negative feedback of TH on TSH production by tumor cells $[2,3]$.

TSH-omas are more fibrotic than other pituitary tumors and it can worsen surgical outcome and somatostatin analog treatment should be considered as the first-line treatment in adults with macroinvasive TSH-omas $[2,4,5]$. Such an adenoma is infrequent in adults and has rarely been report in children, we describe an 8-yr-old boy with TSH-oma, and his follow-up until final height. The patient and his mother assigned consentient term.

\section{Case Presentation}

A 7.9-yr-old white pre-pubertal boy was referred to Pediatric Endocrinology Unit due to goiter. His mother noticed he was more irritable, and lost weight albeit an increased appetite. History was negative for insomnia, headache or visual disturbance. Physical examination disclosed a lean and hyperactive child with stare opened eyes, warm and moist hands, with fine tremors. Height was $138 \mathrm{~cm}$ (1.78SDS; target height $-0.96 \mathrm{SDS})$, weight $27.2 \mathrm{~kg}$ (0.40SDS), and BMI 14.28 (-1.14SDS). Pulse rate was regular $(108 \mathrm{bpm})$ and blood pressure $100 / 60 \mathrm{mmHg}$. Thyroid was tender, diffusely enlarged (app.30g). Deep tendon reflexes were exacerbated. Laboratory work-up revealed a bone age (BA, Greulich \& Pyle) of 9-yr, and the following thyroid function profile (normal values in brackets) was found: $\mathrm{TT}_{3} 181.9$ (45-

Table 1: Preoperative clinical and laboratory events.

\begin{tabular}{|c|c|c|c|c|c|c|}
\hline CA (yr) & Symptons and signs & TT3 (ng/dL) & TT4 (mg/dL) & fT4 (ng/dL) & TSH $(\mathrm{mU} / \mathrm{mL})$ & Treatment \\
\hline 6.8 & Goiter & 201.8 & 16.8 & & 4.66 & \\
\hline 7.9 & $\begin{array}{c}\text { Goiter, tachycardia, tremors, } \\
\text { emaciation }\end{array}$ & 181.9 & 24 & 3.68 & 4.77 & Propranolol \\
\hline 8.1 & & 205.5 & & 2.64 & 4.15 & Methimazole started \\
\hline 8.6 & & & 12.7 & 1.76 & 8.93 & Methimazole \\
\hline 9.3 & & & & 2.74 & 12.59 & Methimazole withdrawn \\
\hline 9.4 & & 432 & 19.9 & 4.7 & 3.22 & TSS \\
\hline Normal range & & $45-137$ & $4.5-12$ & $0.71-1.85$ & $0.49-4.67$ & \\
\hline
\end{tabular}

$\mathrm{CA}=$ Chronological age

Table 2: Pre and post-TSS surgery hormonal profile on TRH and ITT tests.

\begin{tabular}{|c|c|c|c|c|c|c|}
\hline & Time(min) & TSH $(\mathrm{mU} / \mathrm{mL})$ & PRL (ng/mL) & GH (ng/dL) & Cortisol (mg/dL) & Glycaemia (mg/dL) \\
\hline \multirow{5}{*}{ Preoperative } & 0 & 3.22 & 7.7 & 0.7 & 15.2 & 85 \\
\hline & 20 & & & 0.8 & & 28 \\
\hline & 30 & 4.2 & 32.6 & 5.2 & 16.6 & 53 \\
\hline & 40 & & & 5.5 & & 72 \\
\hline & 60 & 3.54 & 26.6 & 5.9 & 24.6 & 84 \\
\hline \multirow{5}{*}{ Postoperative } & 0 & 0.78 & 0.7 & 0.1 & 8.1 & 77 \\
\hline & 20 & & & 0.1 & & 14 \\
\hline & 30 & 1.54 & 1.1 & 0.1 & 12.3 & 36 \\
\hline & 40 & & & 0.2 & & 50 \\
\hline & 60 & 1.3 & 1 & 0.2 & 26.9 & 50 \\
\hline
\end{tabular}




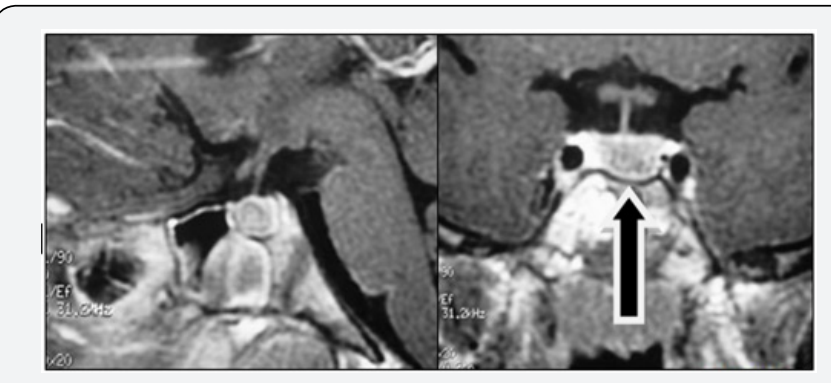

Figure 1: Preoperative pituitary MRI.

vTranssphenoidal surgery (TSS) was performed and a well-demarcated, fibrous and firm adenoma was excised. The pathologic specimen showed adenoma cells that were immunopositively only for TSH and chromogranin and negative for LH, FSH, PRL, ACTH, and GH. Eighteen hours after surgery, serum TSH and $\mathrm{fT}_{4}$ descended to 0.53 and 1.8 , respectively and goiter and thyrotoxicosis signs diminished as well. On the $3^{\text {rd }}$ day postoperatively, acute adrenal insufficiency and transient diabetes ensued. Hydrocortisone and DDAVP were given and maintained for 2 and 14 months, respectively. Two months after TSS, ACTH was 12 (10-50 pg/mL) and IGF-1 64 (74-388 $\mathrm{ng} / \mathrm{mL})$. Peak GH and cortisol $(\mu \mathrm{g} / \mathrm{dL})$ on ITT were 0.2 and 26.9 respectively. PRL and TSH responses to TRH were blunted; however, RAIU was normal (23.8\%). One year after surgery, BA was 11.5, $\mathrm{TT}_{3}, \mathrm{TT}_{4}$ and $\mathrm{fT}_{4}$ were in the low-normal range for age, calorimetry was sub-normal and pituitary MRI showed no evidence of tumor.

He had gained weight, but growth velocity was $<1 \mathrm{~cm} / \mathrm{yr}$ despite adequate replacement dose of l-thyroxine $(88 \mu \mathrm{g} /$ day $)$ He was put on $\mathrm{rhGH}(0,033 \mathrm{mg} / \mathrm{kg} /$ day $)$ and growth velocity improved significantly $(9.2 \mathrm{~cm} / \mathrm{yr})$. Three years after surgery, he is still pre-pubertal and growing normally (on both l-thyroxine and $\mathrm{rGH}$ ). Last pituitary MRI was normal and aSU lower than
0.05 (aSU/TSH 0.61). His BA was 13.0 (chronological age 12.5) and peak LH and FSH after GnRH were 1.1 and $1.4 \mathrm{mU} / \mathrm{mL}$, respectively. At that time, testosterone replacement was started and after 9 months, he was pubertal. Five years after surgery, rhGH was suspended, because he reached height above target height. Six months later, testosterone replacement was stopped. However, pubertal stage did not evolve and IGF-1 was 145 (226$903 \mathrm{ng} / \mathrm{mL}$ ), testosterone (250 mg/month) and rhGH (0.6 mg/ day) were re-started. At his last visit, at 16.3 yr.-old, height was $178.9 \mathrm{~cm}$ (0.59 SDS) and pituitary MRI was normal. Figure 2 shows his height and weight SDS during follow-up and table 3 summarizes main postoperative clinical and laboratory events.

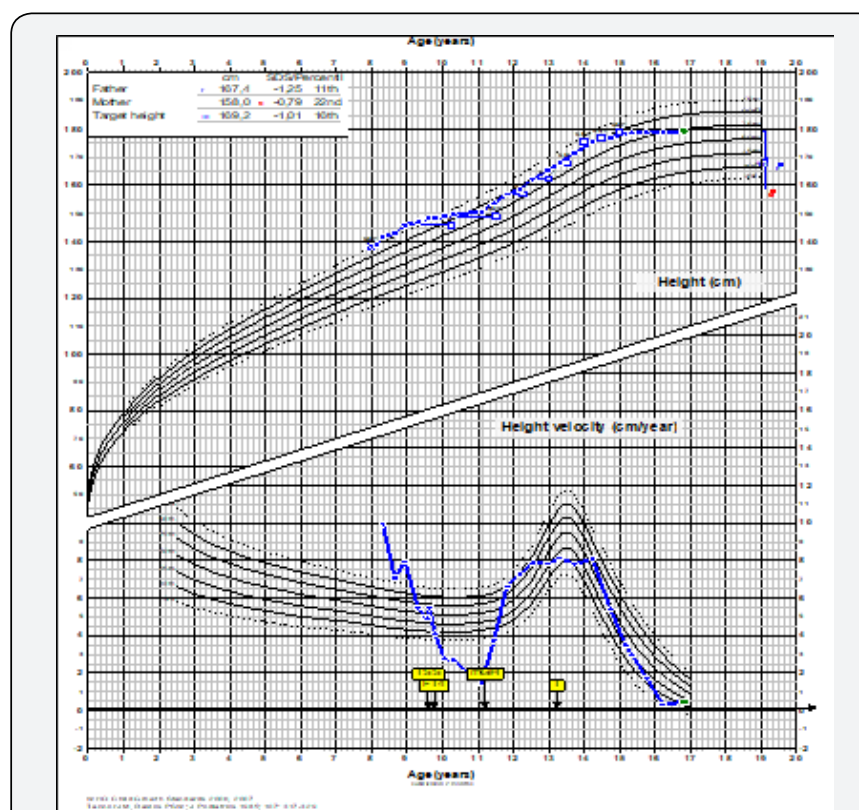

Figure 2: Height and height velocity chart during the follow-up. TSS = transphenoidal surgery; I-T4 = levothyroxine; rhGH = human recombinant growth hormone; $\mathrm{T}=$ testosterone.

Table 3: Main postoperative clinical and laboratory events.

\begin{tabular}{|c|c|c|c|c|c|c|}
\hline $\begin{array}{l}\text { TIME (after } \\
\text { TSS) }\end{array}$ & Symptoms and signs & $\begin{array}{l}\mathrm{TT}_{3}(\mathrm{ng} / \\
\mathrm{dL})\end{array}$ & $\begin{array}{l}\mathrm{TT}_{4}(\mathrm{mg} / \\
\mathrm{dL})\end{array}$ & $\begin{array}{l}\mathrm{fT}_{4}(\mathrm{ng} / \\
\mathrm{dL})\end{array}$ & $\begin{array}{c}\text { TSH (mU/ } \\
\mathrm{mL})\end{array}$ & Treatment \\
\hline $\begin{array}{l}\text { 3rd postopera- } \\
\text { tive day* }\end{array}$ & $\begin{array}{c}\text { Goiter reduction, weakness, anorexia, } \\
\text { polyuria }\end{array}$ & 115 & 8.7 & 1.3 & 0.28 & Hydrocortisone DDAVP \\
\hline 2 months & Diminished goiter & 117 & 8.9 & 1.47 & 0.78 & \\
\hline 12 months & $\begin{array}{l}\text { Weight gain, cool skin, growth failure, } \\
\text { subnormal calorimetry }\end{array}$ & 50.9 & 5.3 & 0.81 & 1.7 & l-thyroxine \\
\hline 14 months & Growth failure & & & & & rhGH started \\
\hline 3 years & Growth acceleration, no puberal signs & & 10.2 & 1.5 & 0.86 & 1-thyroxine rhGH \\
\hline 3.4 years** & $\begin{array}{l}\text { Growth acceleration, no pubertal } \\
\text { signs }\end{array}$ & & 9.6 & 1.63 & & $\begin{array}{l}\text { l-thyroxine rhGH Testoster- } \\
\text { one started }\end{array}$ \\
\hline 5 years & on puberty & 57.1 & 10 & 1.24 & & rhGH suspended \\
\hline 5.5 years & Puberty not evolved & & 11.2 & 1.36 & 2.8 & Testosterone suspended \\
\hline 6 years & & & & & & $\begin{array}{l}\text { Testosterone and rhGH } \\
\text { re-started }\end{array}$ \\
\hline Normal range & & $45-137$ & $4.5-12$ & $0.71-1.85$ & $0.49-4.67$ & \\
\hline
\end{tabular}

*Basal cortisol = $3.43 \mathrm{mg} / \mathrm{dL}$ (6-19); urine density = 1005; ** Total testosterone = $106 \mathrm{ng} / \mathrm{dL}(<100)$; peak LH and FSH after GnRH = $1.1 \mathrm{and}$ $1.4 \mathrm{mU} / \mathrm{mL} ; \mathrm{CA}=$ Chronological age; $\mathrm{BA}=$ bone age; $r \mathrm{hGH}=$ ecombinant human growth hormone. 


\section{Discussion}

Once inappropriate TSH secretion syndrome is identified, specific investigation to differentiate a TSH-oma of RTH is mandatory [2]. In our patient, TSH was not responsive to TRH stimulation test and both aSU and aSU/TSH molar ratio were high. In not previously treated subjects with RTH, the TSH response to TRH is preserved, and aSU/TSH is normal. Moreover, in RTH subjects a decreased secretion of TSH after supraphysiological doses of TH is usually accompanied by a reduction in RAIU [6], what was not observed in our patient. These findings suggest that RTH was not likely. TSH-omas are rare in adults and to our knowledge our patient is one of the youngest children with hyperthyroidism due to TSH-oma ever reported. Other 13 children or adolescents described were 8-yr. or older (8 to 16yr) and had macroadenoma except a 13 yr-old girl who had microadenoma and a 15 yr-old girl whose tumor size was not decribed [7-19].

In this case, pituitary MRI suggested microadenoma, although $88 \%$ of TSH-omas are usually large and invasive $[2,20]$. Patient underwent TSS because the primary goal of treatment of TSHomas is, whenever possible, the complete removal of the tumor [2]. TSH, TH and aSU levels reduced soon after surgery and one week after, patient was euthyroid. TSS was successful in regard the complete removal of the tumor, although in the follow-up central hypothyroidism, and GH, PRL, LH and FSH deficiencies succeeded. Panhypopituitarism and diabetes insipidus also have been reported [14].

The first case of a patient with TSH-oma and normal aSU was described in 1991 [21]. Valdes-Socin et al. observed normal aSU in more than $60 \%$ of the cases. High aSU is often associated with bad prognosis and was found more frequently in macro than in microadenomas [4]. The high percentage of patients with normal aSU could difficult differential diagnosis with RTH. Absence of TSH response to TRH may be suggestive of presence of a TSHoma. In difficult cases, genetic analysis looking for the presence of a mutation in TR $\beta$ gene may easily help to discriminate between the two disorders [2]. SHBG could also be a useful test yet its level was almost invariably normal in patients with RTH but often high in thyrotoxic patients with TSH-oma [2]. One challenging situation is those patients with an invisible adenoma on MRI and near-normal aSU, as initially occurred in our patient, whose diagnosis was done one year after inappropriate treatment with MTZ; possibly, that promoted tumor growth.

This case shows interesting aspects: the age of the patient at diagnosis; the finding of a normal MRI in contraposition to the elevated aSU/TSH molar ratio that was not adequately interpreted; growth of the tumor during MTZ, blunted TSH response to TRH in the post-operative phase in contradiction to diminished calorimetry, low-normal values of fT4, TT4 and TT3, and normal RAIU. We presented a comprehensive evaluation of a patient with TSH-oma followed for more than 8yr, who attained a final height, in accordance with the target height due to adequate therapeutic management.

\section{Learning points}

i. Once inappropriate TSH secretion syndrome is identified, specific investigation to differentiate a TSH-oma of RTH is mandatory, even in children.

ii. Patients who have TSH-oma could be misdiagnosed as having primary hyperthyroidism and, thus, mistakenly treated with antithyroid drugs or thyroid ablation.

iii. TSH-oma may be a microadenoma and be present even when aSU is near-normal or normal and it is a challenging situation.

iv. After surgery, follow-up should be prolonged and hormonal deficiencies should be diagnosed and treated.

\section{References}

1. Beck-Peccoz P, Persani L, Mannavola D, Campi I (2009) Pituitary tumours: TSH-secreting adenomas. Best Pract Res Clin Endocrinol Metab 23(5): 597-606.

2. Amlashi FG, Tritos NA (2016) Thyrotropin-secreting pituitary adenomas: epidemiology, diagnosis, and management. Endocrine 52(3): 427-440.

3. Sanno N, Teramoto A, Osamura RY (2001) Thyrotropin-secreting pituitary adenomas. Clinical and biological heterogeneity and current treatment. J Neurooncol 54(2): 179-186.

4. Valdes-Socin H, Chanson P, Delemer B, Tabarin A, Rohmer V, et al. (2003) The changing spectrum of TSH-secreting pituitary adenomas: diagnosis and management in 43 patients. Eur J Endocrinol 148(4): 433-442.

5. Ness-Abramof R, Ishay A, Harel G, Sylvetzky N, Baron E, et al. (2007) TSH-secreting pituitary adenomas: follow-up of 11 cases and review of the literature. Pituitary 10(3): 307-310.

6. Refetoff S, Weiss RE, Usala SJ (1993) The syndromes of resistance to thyroid hormone. Endocr Rev 14(3): 348-399.

7. Rabbiosi S, Peroni E, Tronconi GM, Chiumello G, Losa M, et al. (2012) Asymptomatic thyrotropin-secreting pituitary macroadenoma in a 13-year-old girl: successful first-line treatment with somatostatin analogs. Thyroid 22(10): 1076-1079.

8. Brucker-Davis F, Oldfield EH, Skarulis MC, Doppman JL, Weintraub BD (1999) Thyrotropin-secreting pituitary tumors: diagnostic criteria, thyroid hormone sensivity, and treatment outcome in 25 patients followed at the National Institutes of Health. J Clin Endocrinol Metab 84(2): 476-486

9. Korn EA, Gaich G, Brines M, Carpenter TO (1994) Thyrotropin-secreting adenoma in an adolescent girl without increased serum thyrotropinalpha. Horm Res 42: 120-123.

10. Nyhan WL, Green M (1964) Hyperthyroidism in a patient with a pituitary adenoma. J Pediatr 65: 583-589.

11. Suntornlohanakul S, Vasiknanont P, Mo-Suwan L, Phuenpathom N, Chongchitnant N (1900) TSH secreting pituitary adenoma in children: a case report. J Med Assoc Thai 73(3): 175-178.

12. Polak M, Bertherat J, Li JY, Kujas M, Le Dafniet M, et al. (1991) A human TSH-secreting adenoma: endocrine, biochemical and morphological studies. Evidence of somatostatin receptors by using quantitative autoradiography. Clinical and biological improvement by SMS 201-995 treatment. Acta Endocrinol (Copenh) 124(4): 479-486.

13. Avramides A, Karapiperis A, Triantafyllidou E, Vayas S, Moshidou A, et al. (1992) TSH-secreting pituitary macroadenoma in an 11-year-old girl. Acta Paediatr 81(12): 1058-1060. 
14. Phillip M, Hershkovitz E, Kornmehl P, Cohen A, Leiberman E (1995) Thyrotropin secreting pituitary adenoma associated with hypopituitarism and diabetes insipidus in an adolescent boy. J Pediatr Endocrinol Metab 8(1): 47-50.

15. Gannage MH, Maacaron C, Okais N, Halaby G (1997) Adenome hypophysaire a TSH. A propos d'un cas. J Med Liban 45: 97-101.

16. Safer JD, Colan SD, Fraser LM, Wondisford FE (2001) A pituitary tumor in a patient with thyroid hormone resistance: a diagnostic dilemma. Thyroid 11(3): 281-291.

17. Kessler M, David R, Pawelczak M, Hanono A, Shah B (2010) Thyrotropinsecreting pituitary adenoma in an adolescent boy: challenges in management. Pediatrics 126(2): e474-478.

18. Nakayama Y, Jinguji S, Kumakura S, Nagasaki K, Natsumeda M, et al. (2012) Thyroid-stimulating hormone (thyrotropin)-secretion pituitary adenoma in an 8-year-old boy: case report. Pituitary 15(1): 110-115.
19. Mazerkina N, Trunin Y, Gorelyshev S, Golanov A, Kadashev B, et al. (2016) Thyrotropin-secreting pituitary adenoma in an 11-year-old boy with type 1 autoimmune polyglandular syndrome. J Pediatr Endocrinol Metab 29(2): 237-240.

20. Sarlis NJ, Gourgiotis L, Koch CA, Skarulis MC, Brucker-Davis F, et al. (2003) MR imaging features of thyrotropin-secreting pituitary adenomas at initial presentation. AJR Am J Roentgenol 181(2): 577582.

21. Beckers A, Abs R, Mahler C, Vandalem JL, Pirens G, et al. (1991) Thyrotropin-secreting pituitary adenomas: report of seven cases. J Clin Endocrinol Metab 72(2): 477-483. 